\title{
COMPUTATIONAL MODELING OF PERPENDICULAR TO GRAIN STRESS IN A NON-STANDARD GLULAM BEAM
}

\author{
W. Gilewski ${ }^{*}$, A. Al Sabouni-Zawadzka** ${ }^{* *}$, Pelczynski ${ }^{* * *}$
}

\begin{abstract}
This paper focuses on the analysis of tensile stresses perpendicular to the grain in simply supported beams with different geometry made of glued laminated timber. Two types of beams are considered: standard double-tapered beams described in Eurocode 5 and non-standard glulam beams with a flattened apex. The beams are analysed using two methodology approaches: a code design verification method and a finite element method (FEM) in terms of the linear theory of elasticity with plane stress assumption. The performed analyses proved that both methodologies lead to consistent results in case of standard glulam beams and therefore, the FEM can be used in case of non-standard structures, which are not included in Eurocode 5. Moreover, the FE analysis of the glulam beam with a flattened apex showed that it can be treated as a structure with two apex zones.
\end{abstract}

Keywords: non-standard beam, FEM, glued laminated timber, perpendicular to grain stress

\section{Introduction}

Simply supported beams are one of the most commonly used structural members in timber engineering. They can be tapered or have constant cross-section. Tapered beams are often used as roof elements, as their geometry naturally provides a desired roof inclination. Furthermore, the material of such beams is used with better efficiency, because the geometry tends to reflect the bending stress distribution under most load cases. In this paper double-tapered glulam beams are considered, with a standard geometry described in Eurocode 5 (EN 1995-1-1:2004). In the design and analysis of such beams, apart from shear and bending stresses, tensile stress perpendicular to the wood fibres should be taken into account and reinforcement against this stress should be considered if needed (Danielsson, 2013; Danielsson, 2013a; Franke et al., 2015; Thelandersson, 2003; Umaima Muhammed, 2015 and Vratusa et al., 2011).

According to the design standard (EN 1995-1-1:2004) normal stress perpendicular to grain should be evaluated in the apex zone, whose width is equal to the apex height. Eurocode 5 provides two alternative formulae for calculation of the stress perpendicular to grain, depending on the load type:

$$
\sigma_{t, 90, d}=k_{p} \frac{6 M_{a p, d}}{b h_{a p}^{2}}, \quad \sigma_{t, 90, d}=k_{p} \frac{6 M_{a p, d}}{b h_{a p}^{2}}-0,6 \frac{p_{d}}{b},
$$

where: $M_{\alpha p, d}$ is the design moment at the apex, $b$ is the width of the beam, $h_{\alpha p}$ is the height of the beam at the apex, $p_{d}$ is the uniformly distributed load acting on the top of the beam over the apex area and $k_{p}=0.2 \tan \left(\alpha_{a p}\right)$. Whereas the first expression $(1)_{1}$ is accepted and recommended (unless the National annex states otherwise) for all load cases, the second one $(1)_{2}$ may be used only when the beam is loaded with a uniform load applied to the top of the apex zone.

\footnotetext{
Prof. Wojciech Gilewski, PhD.: Faculty of Civil Engineering, Warsaw University of Technology, Al. Armii Ludowej 16; 00637 Warsaw; Poland, w.gilewski@il.pw.edu.pl

** Anna Al Sabouni-Zawadzka, PhD.: Faculty of Civil Engineering, Warsaw University of Technology, Al. Armii Ludowej 16; 00-637 Warsaw; Poland, a.sabouni@il.pw.edu.pl

*** Jan Pelczynski, MSc.: Faculty of Civil Engineering, Warsaw University of Technology, Al. Armii Ludowej 16; 00-637 Warsaw; Poland, j.pelczynski@il.pw.edu.pl
} 
According to Eurocode 5, the biggest tensile stress perpendicular to the grain should satisfy the expression $\sigma_{t, 90, d} \leq k_{d i s} k_{v o l} f_{t, 90, d}$, where: $f_{t, 90, d}$ is the design tensile strength perpendicular to grain, $k_{\text {dis }}$ is a factor which takes into account the effect of the stress distribution in the apex zone and for double-tapered beams equals 1.4, $k_{v o l}$ is a volume factor given by $k_{v o l}=\left(V_{0} / V\right)^{0,2}$, where: $V_{0}$ is the reference volume of $0.01 \mathrm{~m}^{3}$, $V$ is the volume of the apex zone and should not be taken greater than $2 V_{b} / 3$, where $V_{b}$ is the total volume of the beam.

In the present paper, two types of beams are compared: a standard beam - a simply supported doubletapered glulam beam with varying apex height, which was also considered by Gilewski (2017) and a nonstandard beam - a simply supported glulam beam with a non-standardized geometry (a flattened apex) (Fig. 1).

The purpose of this study is to determine the level and distribution of normal stresses perpendicular to the grain in the analysed examples of glulam beams and to find a proper approach to the analysis of nonstandard beams. The structures were analysed using two methods: the design code verification (EN 19951-1:2004) and the finite element method (FEM) (Mackerle, 2005 and Zienkiewicz, 2000).

\section{Standard double-tapered beams}

Gilewski (2017) considered an example of a standard double-tapered beam made of glued laminated timber GL28h. The authors presented a comparison of beams with various heights and various material parameters changing linearly from isotropy to orthotropy. Two load cases were considered: a uniformly distributed load acting on the top of the beam and two concentrated forces applied in $1 / 4$ and 3/4 of the beam span.

According to Eurocode 5, tensile stresses perpendicular to the grain appear in the whole apex zone and as a result this zone should be considered for additional reinforcement, which shall be designed globally in the whole area. The fact is confirmed by the finite element analysis made by Gilewski (2017).

\section{A non-standard beam}

\subsection{Design code verification}

The analysed non-standard beam (Fig. 1) is made of glued laminated timber GL28h. Geometry of the beam is presented in Fig. 1. In order to apply the design code verification method for the non-standardized geometry of the beam it is assumed that both ends of the flattened area are apex zones.

The calculations were performed for the section A-A1 (Fig. 1) with the internal forces: $M_{A 1}=6234 \mathrm{kNm}$, $V_{A 1}=403 \mathrm{kN}$. The radial tensile stresses were calculated using the expressions given in Eurocode 5:

$$
\begin{aligned}
& \sigma_{m, d, A 1}=\frac{6 M_{A 1}}{b h^{2}}=\frac{6 \cdot 623400}{52 \cdot 310^{2}}=0,748 \frac{\mathrm{kN}}{\mathrm{cm}^{2}}=7,48 \mathrm{MPa}, \\
& \sigma_{t, 90, d, A 1}=\sigma_{m, d, A 1} \cdot 0,2 \cdot \operatorname{tg} \alpha=7,48 \cdot 0,2 \cdot \operatorname{tg}(7.68)=0,20 \mathrm{MPa} .
\end{aligned}
$$

Condition for the radial tensile stresses in the tapered area:

$$
\begin{aligned}
& f_{t, 90, d}=k_{d i s}\left(\frac{V_{0}}{V}\right)^{0,2} \frac{k_{\mathrm{mod}} f_{t, 90, k}}{\gamma_{M}}=1,4 \cdot\left(\frac{0,01}{0,52 \cdot 3,10^{2}}\right)^{0,2} \cdot \frac{0,8 \cdot 0,45}{1,25}=0,12 \mathrm{MPa}, \\
& \sigma_{t, 90, d, A 1}=0,20 \mathrm{MPa}>f_{t, 90, d}=0,12 \mathrm{MPa} \quad(167 \%) .
\end{aligned}
$$

Timber tensile strength perpendicular to the grain is exceeded and as a result local reinforcement of the tapered area should be considered.

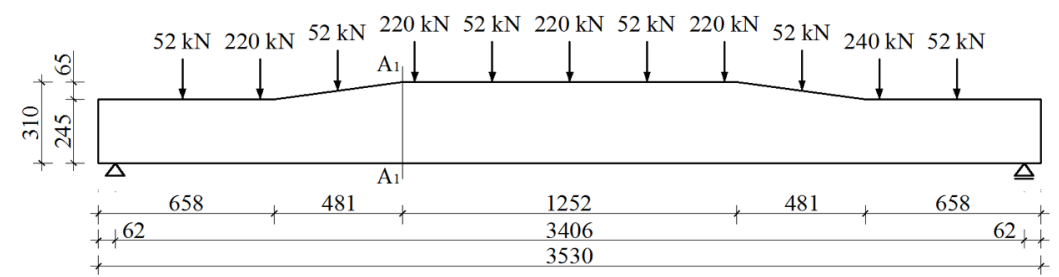

Fig. 1: Non-standard beam with geometry, support scheme and loads. 


\subsection{Finite element analysis}

In order to determine distribution of normal tensile stress perpendicular to the grain in the non-standard beam a finite element analysis is required. The area of radial tensile stress is estimated by the finite element method with the use of Abaqus software. Based on the literature and own scientific papers (Danielsson, 2010 and Gilewski, 2017) the following assumptions are applied to the further analysis:

1) If orthotropic properties of the material are applied the normal stress is smaller than the one obtained from the design standards calculations. The phenomena is better seen in the case of beams with flattened apex and under the distributed load rather than the concentrated one. The maximum values received for isotropy are the closest most clear to the design standards results.

2) The areas of radial tensile stress determined for various orthotropic properties of glulam are similar in shape and range. The calculations for isotropy provide the biggest area which is the most safe approach in the context of uncertainties of computational parameters.

3) Taking into account the conclusions from computational analysis, the calculations in the beam under consideration (in which combination of distributed and concentrated load is applied) are provided for the most safe case which is isotropy.

The results for isotropy are presented in Fig. 2. Distribution of stress is nearly symmetric and values for both apex areas are similar. Therefore, further considerations concern the left side of the beam.

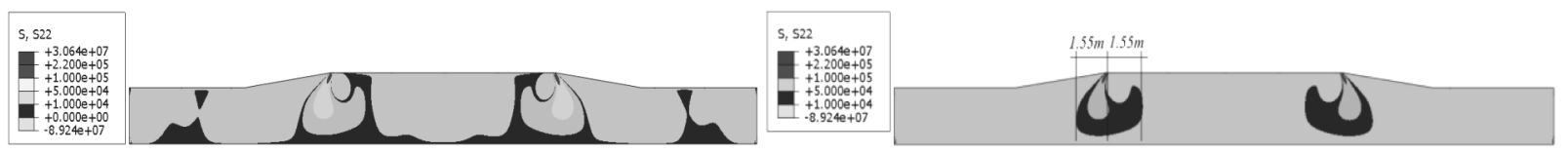

Fig. 2: Distribution of positive normal stress perpendicular to grain: a) full range, b) the range of stress less than $5 \%$ of the maximum value.

To define the area in the horizontal direction the stresses smaller than $0.01 \mathrm{MPa}$ are omitted $(5 \%$ of maximum stress). Taking into account the possibility of delamination, possible redistribution of stress after delamination and uncertainties of computational data, the reinforcement should also be considered in the right side of the area from the apex (Fig. 2b), where the positive stress is relatively small.

Because of a non-uniform distribution of stress, it is assumed that the $20 \%$ of the area placed in the middle of the area marked in the Fig. $2 \mathrm{~b}$ is the most dangerous.

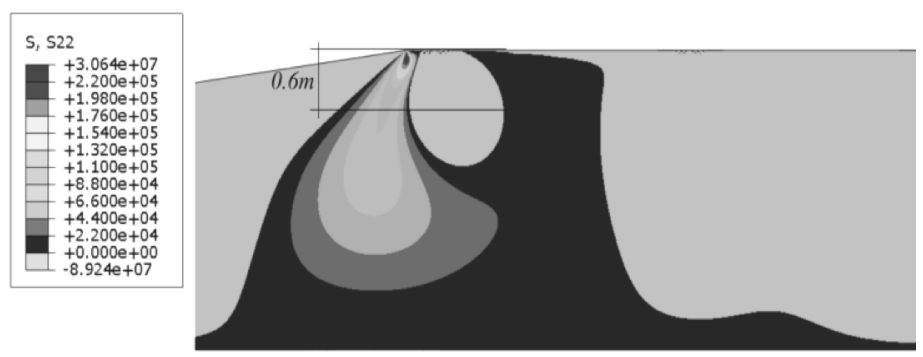

Fig. 3: The range to be reinforced in vertical direction.

a)

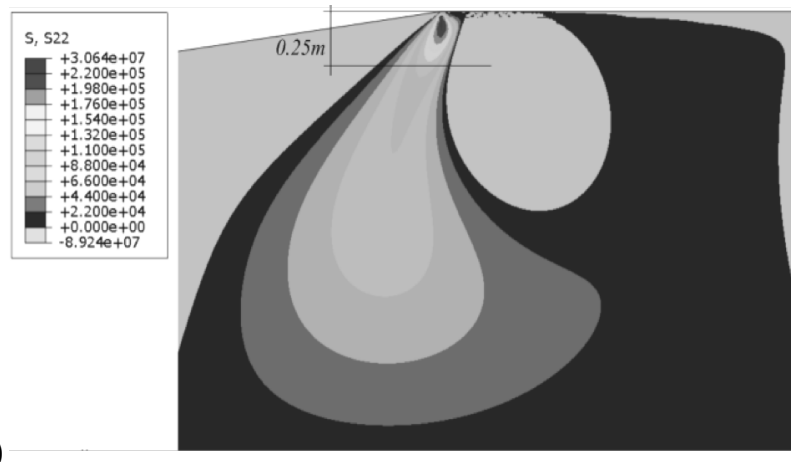

b)

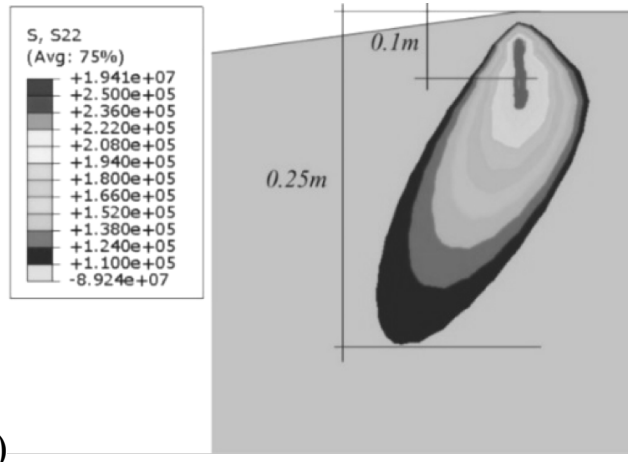

Fig. 4: The range of stress with the value bigger than 0.12 MPa: a) a wider view, b) a detail. 
Distribution of positive normal stress is non-uniform also in the vertical direction (Fig. 3) Below $0.6 \mathrm{~m}$ from the flattened area the stress does not exceed $80 \%$ of the value accepted by the design standard. It is assumed that the area below is the zone of anchorage. The length of reinforced screws should be $1.20 \mathrm{~m}$.

Maximum normal tensile stress perpendicular to the grain of the glulam is on the level $0.10 \mathrm{~m}$ from the flattened area (Fig. 4). For the design of the reinforcement it is recommended to check the design conditions on the level $0.10 \mathrm{~m}$ and $0.25 \mathrm{~m}$ from the flattened area (because of significant shear stress in the apex area).

\section{Conclusions}

The design and structural analysis of tapered beams made of glued laminated timber require taking into account tensile stress perpendicular to the wood fibres. According to the design standard (EN 1995-1$1: 2004)$ such stresses should be evaluated in the apex zone, which has a width equal to the apex height. Eurocode 5, however, applies only to limited number of beam shapes. In case of non-standard geometry there are no standardized rules or formulas that can be applied.

The analyses performed for the purpose of this paper aimed at finding an efficient tool for the analysis of non-standard glulam beams. For this purpose, a finite element analysis was used. Taking into account determination of the zones where the potential reinforcement against radial tensile stresses is needed, the results obtained from the FE analysis of a standard double-tapered beam were consistent with the ones from the design code verification. They confirmed that the reinforcement should be considered globally in the whole apex zone.

In case of non-standard beams, the finite element analysis can be used to determine distributions and values of tensile stress perpendicular to the grain and to indicate areas that should be reinforced.

The FE analysis of the glulam beam with a flattened apex showed that such a beam can be treated as a structure with two apex zones. However, because of the distribution of the analysed stress the reinforcement should be considered locally in the areas which are dangerous from the point of view of radial tensile stresses.

\section{References}

ABAQUS Documentation 2017.

Danielsson, H. (2013) Perpendicular to grain fracture analysis of wooden structural elements. Models and applications. PhD Thesis, Lund University, Lund, Sweden.

Danielsson, H. and Gustafsson, P.J. (2013) A three dimensional plasticity model for perpendicular to grain cohesive fracture in wood. Engineering Fracture Mechanics, 98, pp. 137-152.

Danielsson, H. (2010) Design and perpendicular to grain tensile stress in double-tapered glulam beams. Internal Report, Lund University, Lund, Sweden.

Franke, S., Franke, B. and Harte, A.M. (2015) Failure modes and reinforcement techniques for timber beams - State of the art. Construction and Building Materials, 97, pp. 2-13.

Gilewski, W. and Pelczynski, J. (2017) On the influence of orthotropy for perpendicular to grain stress in glulam beams, in: Proc. Engineering Mechanics Conference, Svratka, Czech Republic.

Mackerle, J. (2005) Finite element analysis in wood research: a bibliography. Wood Science and Technology, 39, pp. 579-600.

Thelandersson, S. and Larsen, H.J. (2003) Timber Engineering. John Wiley \& Sons, Chichester, England.

Umaima Muhammed, C.K. and Arya, R. (2015) Analytical study on flexural behavior of glued laminated timber. International Journal of Innovative Research in Science, Engineering and Technology, 4, pp. 2485-2493.

Vratusa, S., Kitek, M. and Kilar, V. (2011) Structural particulars of glued laminated beams of variable height. Drewno 54, pp. 19-38.

Zienkiewicz, O.C. and Taylor, R.L. (2000) The finite element method. Vol. 1. The basis. Butterworth-Heinemann, New Jersey.

EN 1995-1-1:2004. Eurocode 5: Design of timber structures - Part 1-1: General - Common rules and rules for buildings.

EN 14080:2013. Timber structures. Glued laminated timber and glued solid timber. Requirements. 